\title{
Roles of Endocannabinoids in Heterosynaptic Long-Term Depression of Excitatory Synaptic Transmission in Visual Cortex of Young Mice
}

\author{
Yan Huang, ${ }^{1,2}$ Hiroki Yasuda, ${ }^{3}$ Abdolrahman Sarihi, ${ }^{1}$ and Tadaharu Tsumoto ${ }^{1}$ \\ ${ }^{1}$ Brain Science Institute, RIKEN, Wako 351-0198, Japan, 2Division of Neurophysiology, Osaka University Graduate School of Medicine, Suita 565-0871, \\ Japan, and ${ }^{3}$ Education and Research Center, Gunma University Graduate School of Medicine, Maebashi 371-8511, Japan
}

\begin{abstract}
Tetanic stimulation of one of two afferent pathways converging to neurons in the visual cortex induces long-term depression (LTD) of synaptic transmission in the other, nonactivated pathway under a certain condition. This form of synaptic plasticity called heterosynaptic LTD (hetero-LTD) was not systematically investigated in previous studies, whereas homosynaptic LTD has been extensively studied. To determine whether hetero-LTD is induced in visual cortical slices of mice and, if so, through what mechanisms, we recorded EPSPs evoked in layer II/III neurons by alternating test stimulation of two sites in layer IV at $0.05 \mathrm{~Hz}$. After theta-burst stimulation of one site, EPSPs evoked by test stimulation of the other site were depressed for a long time in most of the neurons, whereas homosynaptic long-term potentiation was induced at activated synapses. Such a hetero-LTD was induced in most mice at postnatal day 7-20 (P7-P20), but not induced in mice at $\mathrm{P} 35-\mathrm{P} 41$. Tests using the paired-pulse stimulation protocol and coefficient of variation analysis suggested that hetero-LTD was expressed at presynaptic sites. Pharmacological analysis indicated that this form of LTD was induced through activation of the type 5 of metabotropic glutamate receptors, not through the NMDA type of glutamate receptors. Additional analysis using a cannabinoid type 1 receptor agonist and an antagonist suggested that endocannabinoids (eCBs) are involved in this type of LTD. Moreover, results suggest that brain-derived neurotrophic factor, which may be released from strongly activated presynaptic sites, prevents eCBs from suppressing the release of transmitters from these sites.
\end{abstract}

Key words: developing visual cortex; heterosynaptic LTD; endocannabinoids; BDNF; metabotropic glutamate receptor; LTP

\section{Introduction}

In the visual cortex and hippocampus, it was reported that tetanic or repetitive stimulation of one of two afferent pathways converging to postsynaptic neurons induces long-term depression (LTD) of synaptic transmission in the other, nonactivated pathway (Levy and Steward, 1979; Tsumoto and Suda, 1979; Abraham and Goddard, 1983; Tamura et al., 1992; Doyère et al., 1997) (for review, see Linden and Connor, 1995; Bear and Abraham, 1996). In the visual cortex, this heterosynaptic LTD (heteroLTD) is hypothesized to play a role in modification of neural circuits after monocular visual deprivation during a certain period of postnatal development (for review, see Tsumoto, 1992; Bear, 2003), although such a hypothesis was not fully substantiated by experiments so far, and rather homosynaptic LTD (homo-LTD) was suggested to play such a role (Rittenhouse et al., 1999; Heynen et al., 2003) (but see Hensch, 2005). Mechanisms underlying homo-LTD in the visual cortex are suggested to

Received Feb. 29, 2008; revised April 29, 2008; accepted May 31, 2008.

This work was supported in part by Grants-in-Aid from the Ministry of Education, Culture, Sports, Science, and Technology of Japan. We thank Drs. Kazuhiro Sohya, Bin Jiang, and Katsuro Kameyama for technical advice on patch-clamp recordings and data analysis.

Correspondence should be addressed to Dr. Tadaharu Tsumoto, Brain Science Institute, RIKEN, Wako 351-0198, Japan. E-mail: tsumoto@brain.riken.jp.

DOI:10.1523/JNEUROSCI.0899-08.2008

Copyright $\odot 2008$ Society for Neuroscience $\quad$ 0270-6474/08/287074-10\$15.00/0 involve the postsynaptic $\mathrm{Ca}^{2+}$ influx mostly through activated NMDA receptors, dephosphorylation of protein kinase substrates, and clathrin-dependent internalization of AMPA receptors (Heynen et al., 2003) (for review, see Malenka and Bear, 2004). To the best of our knowledge, however, mechanisms underlying hetero-LTD in the visual cortex are not fully understood.

Endocannabinoids (eCBs), endogenous ligands for cannabinoid receptors, play a role in synaptic plasticity in the brain (for review, see Freund et al., 2003; Chevaleyre et al., 2006). For example, eCBs were suggested to play a role in spike timingdependent LTD of synapses in layer $\mathrm{V}$ of the rat visual cortex (Sjöström et al., 2003) or homo-LTD in the mouse striatum (Gerdeman et al., 2002) or in layer II/III of the mouse visual cortex (Crozier et al., 2007). Regarding hetero-LTD, eCBs were also proposed to play a role in this form of LTD at inhibitory synapses in CA1 of the hippocampus (Chevaleyre and Castillo, 2003) and in the basolateral amygdala (Marsicano et al., 2002). Recently, it has been demonstrated that eCBs play an essential role in heteroLTD at excitatory synapses in the immature hippocampus (Yasuda et al., 2008). These results raise questions of whether eCBs are involved in hetero-LTD in the visual cortex and, if involved, how and why eCBs, which are assumed to spread across cell membranes, do not interfere with the induction of homosynaptic long-term potentiation (homo-LTP) at the same neuron.

To address these questions and to elucidate mechanisms un- 
derlying hetero-LTD in the visual cortex, we recorded synaptic responses of neurons in layer II/III to test stimulation alternately administered to two separate sites in layer IV of the cortex. After theta-burst stimulation (TBS) of one site, responses to test stimulation of the other site were depressed for a long time in most of the neurons, whereas homosynaptic LTP was induced at activated synapses. We found that eCBs and its receptor, $\mathrm{CB}_{1} \mathrm{R}$, were involved in hetero-LTD, and brain-derived neurotrophic factor (BDNF), which is assumed to be released from activated terminals, may counteract the action of eCBs so as not to suppress these activated terminals.

\section{Materials and Methods}

Slice preparation. Wild-type mice (C57BL/6), aged from 14 to 20 postnatal days (P14-P20) were used, except in the experiments in which the age dependence of hetero-LTD was tested at P7-P10 and P35-P41. Mice were anesthetized with isoflurane (Abbott) and then decapitated. The brains were rapidly removed and placed in cold oxygenated artificial CSF (ACSF). Coronal slices of the visual cortex ( $350 \mu \mathrm{m}$ thick) were obtained using a tissue slicer (Vibratome 3000; The Vibratome Company). All experimental procedures were performed in accordance with the guidelines of the Animal Experimental Committee of RIKEN Brain Science Institute. Slices were placed in an incubating chamber of oxygenated ACSF at $31^{\circ} \mathrm{C}$ for $1 \mathrm{~h}$ before recording. The recording temperature was $30^{\circ} \mathrm{C}$. ACSF had the following composition (in $\mathrm{mM}$ ): $124 \mathrm{NaCl}, 3.0 \mathrm{KCl}$, 2.0 $\mathrm{CaCl}_{2}, 1.0 \mathrm{MgCl}_{2}, 1.25 \mathrm{NaH}_{2} \mathrm{PO}_{4}, 26.0 \mathrm{NaHCO}_{3}$, and 10.0 glucose, $\mathrm{pH}$ 7.4. ACSF was bubbled continuously with $95 \% \mathrm{O}_{2}-5 \% \mathrm{CO}_{2}$. The flow rate of ACSF was $\sim 2.5 \mathrm{ml} / \mathrm{min}$. Antagonists for GABA receptors were not added to ACSF.

Stimulating electrodes and whole-cell recordings. Two stimulating electrodes of the concentric bipolar type (125 $\mu \mathrm{m}$ diameter, FHC) were placed at separate sites in layer IV of slices, which were vertically cut from the white matter to the bottom of layer II/III. Whole-cell recordings from pyramidal neurons in layer II/III of the visual cortex were performed under infrared differential interference contrast optics. EPSPs evoked by test stimulation of layer IV at $0.05 \mathrm{~Hz}$ were recorded in the current-clamp mode using a multiclamp amplifier (700B; Molecular Devices), filtered at $2-5 \mathrm{kHz}$, digitized at $10 \mathrm{kHz}$, and fed into a Pentium 4 personal computer with a digitizer computer interface (PCI-MIO-16E-4; National Instruments). Data analysis was performed using the Igor 4.01 program.

Recording electrodes were pulled from borosilicate glass capillary with filaments $(0.86 \mathrm{~mm}$ inner diameter, $1.5 \mathrm{~mm}$ outer diameter). The resistance of these electrodes with the following internal solution was 5-7 $\mathrm{M} \Omega$. The composition of the internal solution was as follows (in $\mathrm{mM}$ ): $130 \mathrm{~K}$-gluconate, $10 \mathrm{KCl}, 10 \mathrm{HEPES}, 0.2 \mathrm{EGTA}, 4 \mathrm{MgATP}, 0.5 \mathrm{Na}_{3} \mathrm{GTP}$, and $10 \mathrm{Na}$-phosphocreatine, and adjusted to $\mathrm{pH} 7.2$ with $\mathrm{KOH}$. The osmolarity of the solution was 275-290 mOsm. The input resistance of neurons was continuously monitored throughout the recording by injecting hyperpolarizing test currents ( $-20 \mathrm{pA}$ for $100 \mathrm{~ms})$. The measured resistances were generally $60-100 \mathrm{M} \Omega$, and usually very stable during recordings. If these values changed $>20 \%$, recordings were stopped and the data were discarded. In the experiments in which postsynaptic $\mathrm{Ca}^{2+}$ was chelated, 1,2-bis(2-aminophenoxy)ethane- $N, N, N^{\prime}, N^{\prime}$-tetra-acetic acid (BAPTA) was added at the concentration of $10 \mathrm{~mm}$ to the internal solution of recording electrodes. Similarly, drugs and dimethyl sulfoxide (DMSO) ( $0.1 \%$ in ACSF) as vehicle were added to the internal solution in part of the experiments.

Induction of homo-LTP and hetero-LTD. EPSPs of layer II/III neurons of visual cortical slices were elicited by alternating test stimulation at 0.05 $\mathrm{Hz}$ through two stimulating electrodes positioned in layer IV of the cortex. The intensity of test stimulation was set at 1.5-2.0 times the threshold for eliciting detectable responses $(30-80 \mu \mathrm{A}$ for pulses of $0.1 \mathrm{~ms}$ duration). After recording baseline responses for 5-10 min, TBS paired with postsynaptic depolarization at $0 \mathrm{mV}$ for $40 \mathrm{~s}$ was applied to one site of layer IV. TBS consisted of four trains at $0.1 \mathrm{~Hz}$, each train consisting of 10 bursts at $5 \mathrm{~Hz}$, and each burst consisting of four pulses at $100 \mathrm{~Hz}$. The intensity of each pulse was twice the test pulse intensity. Thereafter, responses to test stimulation at $0.05 \mathrm{~Hz}$ were recorded again for at least 40 min. During TBS, the membrane potentials were clamped at $0 \mathrm{mV}$ in the voltage-clamp mode, except the experiments in which the membrane potentials were clamped at $-70 \mathrm{mV}$ during nonassociative TBS. After TBS, the recordings were performed in the current-clamped mode again.

Analysis of coefficient of variation of EPSPs and paired-pulse ratio. The coefficient of variation (CV) of the peak amplitudes of EPSPs was determined within the stationary period. The stationary periods were 5-10 min before TBS and 15-35 min after TBS, when the peak amplitude of EPSPs was stable. The value of $\mathrm{CV}^{-2}$ was corrected for the variance of background noise, using the relation $\sigma^{2}=\sigma^{2}$ (measured) $-\sigma^{2}$ (noise) (Faber and Korn, 1991). To measure background noise, we used $2 \mathrm{~ms}$ of traces before stimulation. Then, we calculated the normalized $\mathrm{CV}$ and mean to the respective values ( $\mathrm{CV}=\sigma / m$, where $\sigma$ is the $\mathrm{SD}$ and $m$ is the mean). To assess a possible change after TBS, we used separate blocks of 15-30 (mostly 30) traces for the baseline value before TBS and 30-60 (mostly 60) traces 15-35 min after TBS.

The paired-pulse ratio (PPR) of EPSPs was determined as the peak amplitude of averaged traces (10-25 sweeps) of the second EPSPs to that of the first EPSPs.

Drugs. Drugs were applied either through the perfusion medium or the internal solution of recording pipettes. When drugs were applied through the internal solution, control recordings using the internal solution alone or the vehicle (DMSO solution) alone were performed in slices from the same mice as used for test recordings. In the case of bath application, interleaved control recordings were performed in non-drugtreated slices from the same animals. As selective antagonists for the respective type of glutamate receptors, we used the following drugs: D,L2-amino-5-phosphonovaleric acid (APV) (Sigma-Aldrich) at $100 \mu \mathrm{M}$ for NMDA receptors, 6-cyano-7-nitroquinoxaline-2,3-dione (CNQX) (Sigma-Aldrich) at $20 \mu \mathrm{M}$ for AMPA receptors, $(2 S)$-amino-2-[(1S,2S)2-carboxycycloprop-1-yl]-3-(xanth-9-yl)propanoic acid (LY341495) (Tocris Bioscience) at $100 \mu \mathrm{M}$ for metabotropic types of glutamate receptors (mGluRs), 2-methyl-6-(phenylethynyl)pyridine hydrochloride (MPEP) (Tocris Bioscience) at $10 \mu \mathrm{M}$ for the type 5 of mGluRs (mGluR5). As the selective agonist and antagonist for the type 1 of cannabinoid receptor $\left(\mathrm{CB}_{1} \mathrm{R}\right)$, we used $R$ - $(+)$-(2,3-dihydro5-methyl-3-[(4-morpholinyl)methyl]pyrol[1,2,3-de]-1,4-benzoxazin6-yl)(1-naphthalenyl) methanone mesylate [WIN55,212-2 (WIN)] (Tocris Bioscience) at $2 \mu \mathrm{M}$, and $N$-(piperidin-1-yl)-5-(4-iodophenyl)1-(2,4-dichlorophenyl)-4-methyl-1 $H$-pyrazole-3-carboxamide (AM251) (Tocris Bioscience) at $5 \mu \mathrm{M}$, respectively.

In the experiments in which BDNF and its high-affinity receptor were examined, human recombinant BDNF (Regeneron Pharmaceutical) at $400 \mathrm{ng} / \mathrm{ml}$, or anti-TrkB IgG (rabbit polyclonal IgG; Millipore) at 10 $\mu \mathrm{g} / \mathrm{ml}$, were applied through the bath medium containing $0.1 \%$ bovine serum albumin. To infiltrate those proteins into tissues sufficiently, slices were incubated in BDNF solution $(200 \mathrm{ng} / \mathrm{ml})$ for at least $1 \mathrm{~h}$ or in TrkB-IgG solution $(3 \mu \mathrm{g} / \mathrm{ml})$ for at least $2 \mathrm{~h}$ before recording.

Statistical analysis. In the present study, values are given as mean \pm SEM, unless otherwise mentioned. For statistical analysis, values before and after TBS obtained from the same cell and values between two groups of cells were compared by the paired and unpaired t tests, respectively, when values showed normal distribution. The statistical evaluation of normal distribution was performed using the Kolmogorov-Smirnov test.

\section{Results}

\section{Separate stimulation of two pathways from layer IV to layer II/III neurons}

To separately activate two pathways from layer IV to layer II/III neurons, we used slices with a vertical cut from the white matter to the bottom of layer II/III of the cortex (Fig. $1 A$ ). In these slices, test stimulation of each site of layer IV elicited synaptic potentials with a short onset latency and a rapid decay (Fig. $1 B$, traces). The mean onset latencies for 18 neurons, which were randomly selected for measurement, were $2.9 \pm 0.1$ (SEM) ms. Such a short latency and a very small fluctuation of the latency (usually within $0.1 \mathrm{~ms}$ ) indicated that the synaptic potentials were elicited mono- 
A

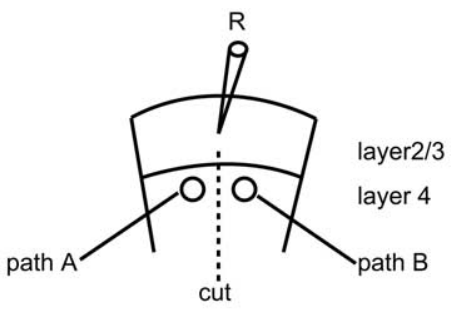

$B \quad$ 1) Paired-pulse stimulation

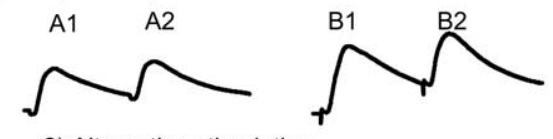

2) Alternative stimulation

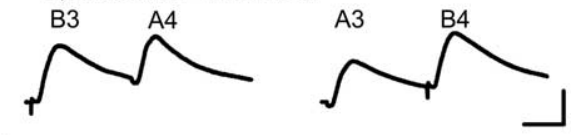

C

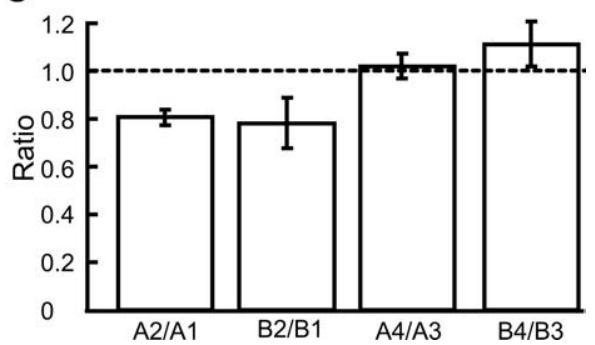

Figure 1. Separate activation of two pathways from layer 4 to layer $2 / 3$ of visual cortex. $A$, Stimulation and recording sites in visual cortical slices, which were transected as shown. $\boldsymbol{B}$, EPSPs evoked by paired pulses applied to the same site at an interval of $50 \mathrm{~ms}$ (top traces) and those to the two different sites alternately at the same interval (bottom traces). Calibration: 20 $\mathrm{ms}, 5 \mathrm{mV}$ (bottom right; applies to all of the records). C, Mean ratios of the amplitudes of the second EPSPs to the first ones evoked by two successive stimulations, as indicated at the abscissa. The number of neurons in each test was seven. The vertical bars indicate SEM.

synaptically. These potentials were almost completely blocked by simultaneous application of CNQX and APV, antagonists for glutamate receptors of the AMPA and NMDA types, respectively, suggesting that the potentials were EPSPs mediated by glutamate.

Then, we examined whether the two pathways converging to recorded neurons were activated separately, using the pairedpulse and primed-pulse stimulation protocol. Initially, pairedpulses at intervals of $50 \mathrm{~ms}$ were applied to the left side (path A) and right side (path B) (Fig. 1A). As shown in the top row of Figure $1 B$, the second responses were smaller than the first responses at both paths A and B (i.e., paired-pulse depression was induced at both sides). Then, the first and second stimuli were applied to the right and left sides, or left and right sides, respectively. As shown in the bottom row of Figure $1 B$, the second responses (A4 and B4) were not smaller than the first responses at the corresponding side ( $\mathrm{A} 3$ and $\mathrm{B} 3$, respectively), indicating that the first stimulus did not affect the responses to the second stimulus. This was confirmed in the group analysis of ratios of the peak amplitude of the second responses to that of the first responses, obtained from seven neurons (Fig. 1C). The mean ratios of the EPSP amplitudes of $\mathrm{A} 2$ to $\mathrm{A} 1, \mathrm{~B} 2$ to $\mathrm{B} 1, \mathrm{~A} 4$ to $\mathrm{A} 3$, and $\mathrm{B} 4$ to $\mathrm{B} 3$ were $0.81 \pm 0.03,0.78 \pm 0.11,1.02 \pm 0.05$, and $1.11 \pm 0.10$, respectively. The latter two values were nearly 1.0 , and significantly ( $p<0.01$, unpaired $t$ test) different from the former two values. These results indicated that the test stimulation at one side did not concomitantly activate the other side.
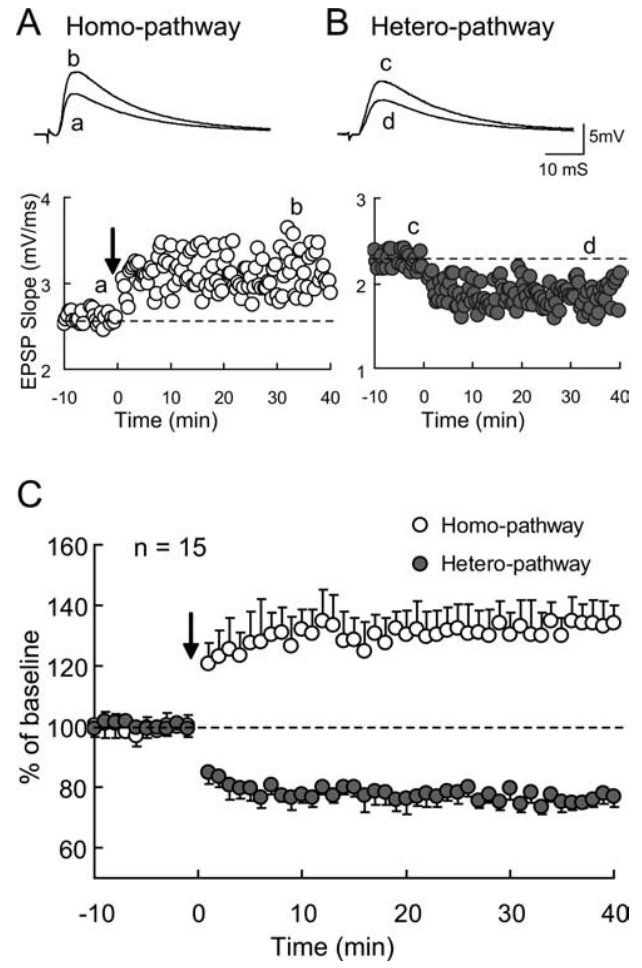

Figure 2. Homosynaptic LTP and heterosynaptic LTD in visual cortex at P14-P20.A, Examples of LTP of homosynaptic EPSPs recorded from a layer II/III neuron in a visual cortical slice at P18. Tetanic stimulation of the theta-burst type was given to the same pathway at time 0 , as indicated by an arrow. Rising slopes of EPSPs were plotted against time. Averaged traces taken at the time indicated by $a$ and $b$ are shown above. $\boldsymbol{B}$, Examples of LTD of heterosynaptic EPSPS recorded from the same neuron as in $A$. Tetanic stimulation of theta-burst type was given to the other pathway at time 0 . Other conventions are the same as those in $\boldsymbol{A}$. $\boldsymbol{C}$, Mean slopes of homosynaptic (open circles) and heterosynaptic (hatched circles) EPSPs normalized to the values before tetanic stimulation $(n=15)$. The vertical bars indicate SEM.

Hetero-LTD was induced simultaneously with homo-LTP

To examine whether TBS applied to one pathway induces longlasting changes in excitatory synaptic transmission in the other, nonactivated pathway (called heterosynaptic pathway), we initially stimulated two sites in layer IV alternately every $10 \mathrm{~s}(0.05$ $\mathrm{Hz}$ at each site) and recorded EPSPs from layer II/III neurons as baseline responses. Then, we applied TBS to one of the pathways when postsynaptic neurons were depolarized to $0 \mathrm{mV}$. This paired TBS elicited a robust LTP in the activated pathway (called homosynaptic pathway) (Fig. $2 \mathrm{~A}$ ). In the heterosynaptic pathway, a weaker, but significant LTD was induced (Fig. $2 B$ ). This was confirmed by the group analysis of 15 neurons (Fig. 2C). For this analysis, we measured the initial, rising slope of EPSPs to elude the possible contamination of GABA-mediated inhibition. The mean EPSP slope 31-35 min after TBS at the activated side was $131.7 \pm 7.8 \%$ of the baseline value, whereas it was $74.9 \pm$ $2.3 \%$ at the nonactivated side. Both values were significantly $(p<0.001$, paired $t$ test) different from the baseline values.

Then, we examined whether TBS without postsynaptic depolarization can induce hetero-LTD. For this, the membrane potential of nine cells was clamped at $-70 \mathrm{mV}$ during TBS, which was applied to one side of layer IV. We found that TBS without postsynaptic depolarization still induced hetero-LTD, whereas it did not induce homo-LTP (supplemental Fig. 1, available at www.jneurosci.org as supplemental material). The mean EPSP slope 31-35 min after TBS at the heterosynaptic pathway was $81.1 \pm 6.8 \%$ of the baseline value for these 9 cells, whereas that for 


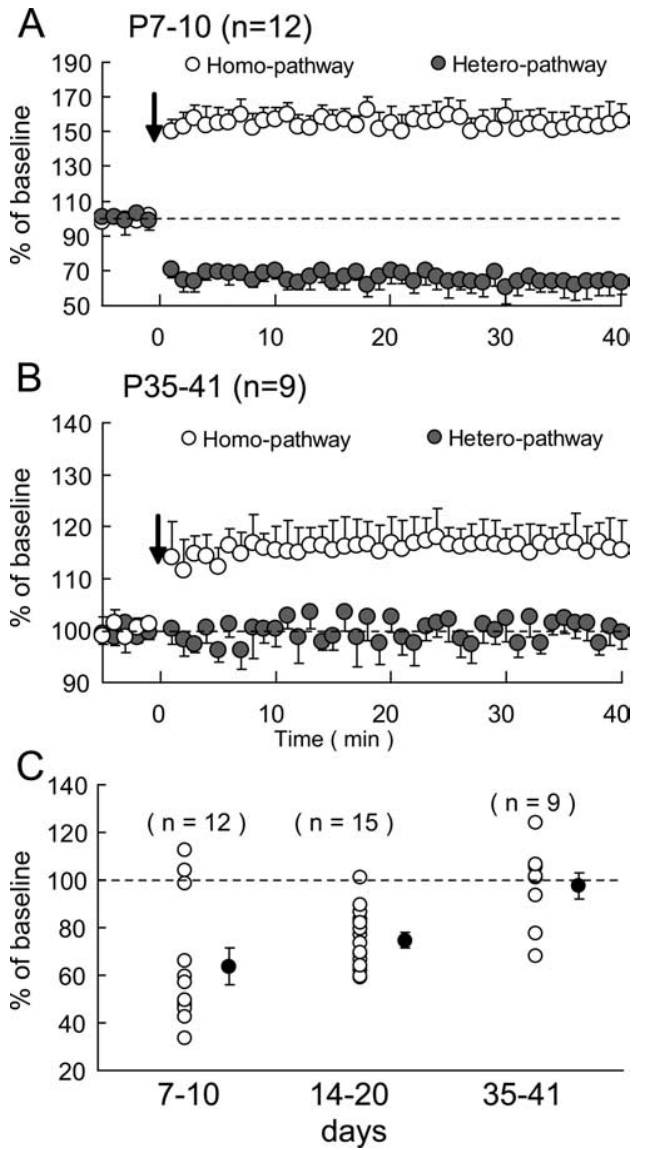

Figure 3. Age-dependent expression of heterosynaptic LTD in visual cortex. $A, B$, Changes in EPSPs after TBS at P7-P10 and P35-P41, respectively. The open and hatched circles show mean EPSP slope values normalized to the pretetanic values for the homosynaptic and heterosynaptic pathways, respectively. Other conventions are the same as those in Figure 2C.C, Developmental changes in the magnitude of heterosynaptic LTD. The mean slope of EPSPs 31-35 min after TBS as percentage of the pretetanic baseline value is plotted for each cell for the three age groups as indicated. The hatched circles and vertical bars show mean \pm SEM for each age group.

12 control cells in which TBS was paired with postsynaptic depolarization was $72.7 \pm 4.8 \%$. The difference between these two values was not significant ( $p>0.05$, unpaired $t$ test). However, the mean value $31-35 \mathrm{~min}$ after TBS at the homosynaptic pathway was $97.1 \pm 7.7 \%$ of the baseline for the 9 cells, whereas that for the 12 cells in which TBS was paired with postsynaptic depolarization was $130.4 \pm 13.8 \%$. The difference between these two values was significant ( $p<0.001$, unpaired $t$ test).

\section{Hetero-LTD is age dependent}

To examine whether there are developmental changes in the induction of hetero-LTD and in its magnitude if induced, we observed changes in EPSPs in the heterosynaptic pathway after TBS of the other pathway in animals at various ages. We found that the largest magnitude of hetero-LTD was induced at P7-P10 (Fig. $3 A$ ). The mean EPSP slope 31-35 min after TBS for 12 neurons was $63.7 \pm 7.6 \%$ of the baseline value. At P14-P20, hetero-LTD at a markedly high magnitude was still induced, as shown in Figure 2C. At P35-P41, no significant hetero-LTD was observed in most of the slices, although a significant homo-LTP was induced (Fig. 3B). To quantify these findings, we plotted the changes in the initial slope of EPSPs in the heterosynaptic pathway 31-35 min after tetanus versus the age of animals (Fig. $3 C$ ). There was a significant age-related decrease in the magnitude of
A. Paired-pulse at hetero-pathway B. CV analysis
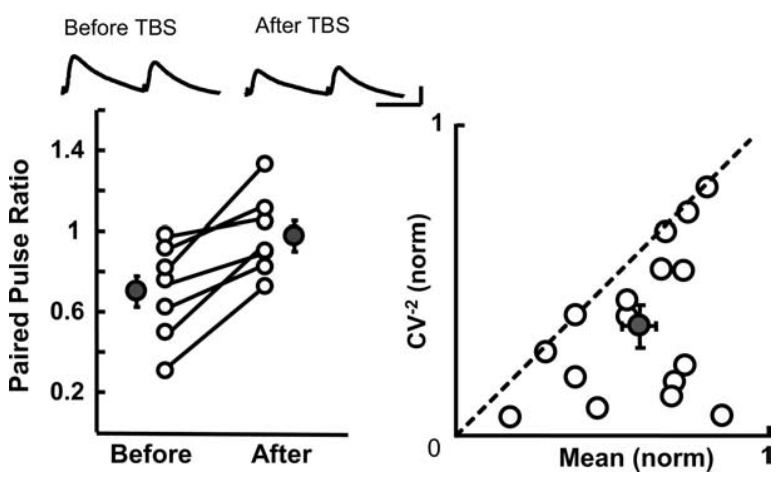

Figure 4. Hetero-LTD may be presynaptic in origin. $\boldsymbol{A}$, Top, Examples of EPSPs in the heterosynaptic pathway, evoked by paired-pulse stimuli at an interval of $100 \mathrm{~ms}$ before and after the induction of hetero-LTD. Averages of 15 consecutive sweeps are shown. Calibration: $50 \mathrm{ms,}$ $5 \mathrm{mV}$ (at right; applies to all of the records). In the bottom graph, the values of paired-pulse ratio before and after the induction of hetero-LTD are connected for each of seven cells. The hatched circles and vertical bars indicate means \pm SEMs. $B, C V$ analysis of changes in the amplitude of EPSPs after the induction of hetero-LTD. Sixteen neurons were selected for this analysis, because they showed significant hetero-LTD. The hatched circle and vertical and horizontal bars indicate mean \pm SEMs, which were $0.36 \pm 0.07$ for the normalized value of $\mathrm{CV}^{-2}$ and $0.57 \pm$ 0.05 for the normalized mean value.

hetero-LTD $(r=0.630 ; n=36 ; p<0.001$; correlation analysis with Statview).

Expression of hetero-LTD may be presynaptic in origin

To determine whether hetero-LTD is expressed presynaptically or postsynaptically, we initially analyzed the PPR of EPSPs. As shown on the top of Figure $4 A$, the first EPSPs evoked by pairedpulse stimulation of the nonactivated site were depressed after TBS, whereas the second EPSPs were not proportionally depressed. Thus, the paired-pulse ratio increased. As shown in the graph of Figure $4 A$, the mean PPRs of the seven cells tested significantly increased after the induction of hetero-LTD. The mean PPR before TBS was $0.70 \pm 0.08$, and that after the induction of hetero-LTD was $0.98 \pm 0.04$. These two values were significantly different $(p<0.01$, paired $t$ test $)$. This result suggests that heteroLTD may be ascribable to changes in presynaptic sites (Zucker, 1989).

To further address the presynaptic and postsynaptic issue, we next performed the CV analysis (Faber and Korn, 1991; Sjöström et al., 2003). On the basis of a binomial model of synaptic transmission, functional changes in presynaptic sites are expected to be accompanied by a change in the $\mathrm{CV}$ of synaptic responses: the values of $\mathrm{CV}^{-2}$ that are plotted against the change in efficacy should be located on or below the diagonal line, if the release probability is low. However, if changes are located purely in postsynaptic sites, the values should be located on the horizontal line of 1.0. As shown in Figure $4 B$, the values for all of the 16 neurons that showed hetero-LTD were located below or on the diagonal line. Thus, the mean value of the normalized $\mathrm{CV}^{-2}$ for the 16 neurons $(0.36 \pm 0.07)$ was below the diagonal line. These results altogether suggest that hetero-LTD is expressed presynaptically.

\section{Hetero-LTD is NMDA receptor independent}

It is well known that the activation of NMDA receptors is necessary to induce homo-LTP at excitatory synapses on pyramidal cells in the visual cortex (Artola and Singer, 1987; Kimura et al., 1989). Thus, we examined whether the activation of NMDA re- 

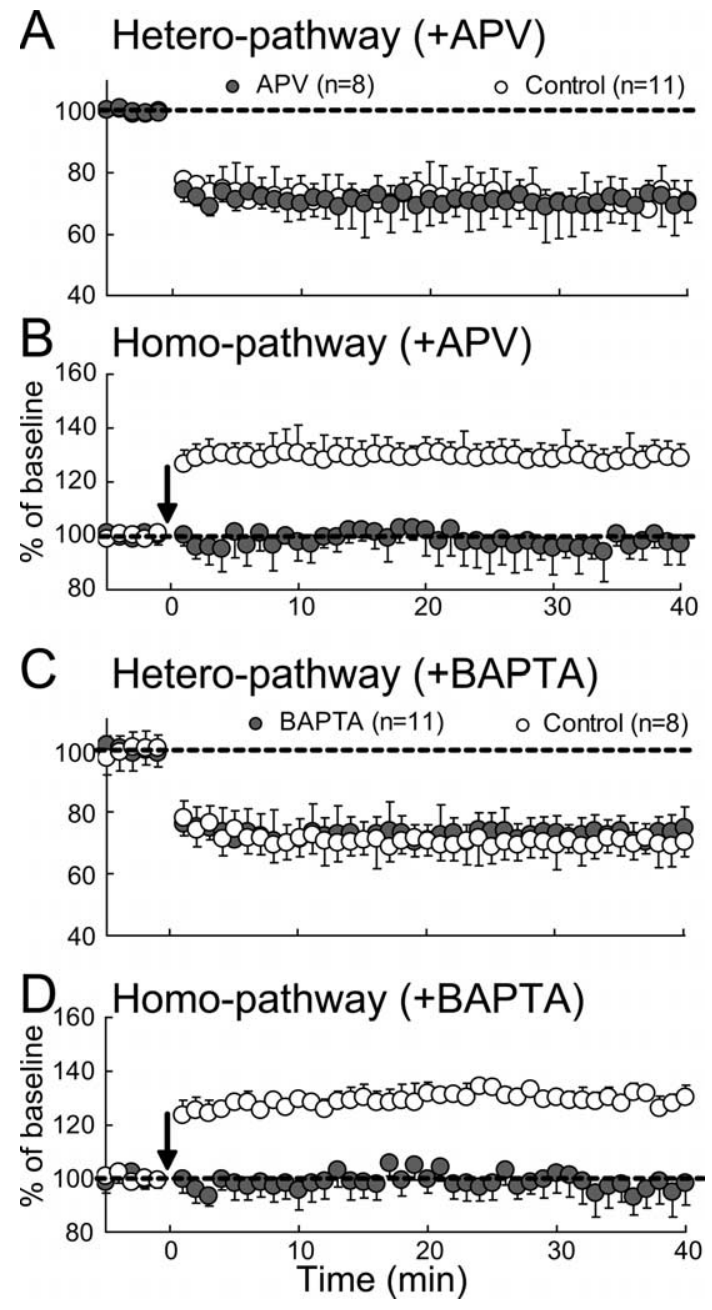

Figure 5. No involvement of NMDA receptors and postsynaptic $\mathrm{Ca}^{2+}$ rise in hetero-LTD. $\boldsymbol{A}$, $\boldsymbol{B}$, Mean EPSP slopes plotted against time for heterosynaptic and homosynaptic pathways, respectively, for 8 APV-treated cells (hatched circles) and 11 control cells (open circles). The slope value was normalized to the pre-TBS value. The vertical bars indicate SEMs. C, D, Mean EPSP slopes for heterosynaptic and homosynaptic pathways, respectively, for 11 BAPTA-filled cells (hatched circles) and 8 control cells (open circles). Other conventions are the same as those in $A$.

ceptors is also necessary for the induction of hetero-LTD, using an antagonist for NMDA receptors, APV. As shown in Figure $5 A$ (hatched circles), APV did not block the induction of heteroLTD. The mean ratios of EPSP slope 31-35 min after TBS to that before TBS were $71.3 \pm 8.0 \%(n=8)$ with APV and $69.3 \pm 7.6 \%$ $(n=11)$ without APV. The difference between these two values was not significant ( $p>0.1$, unpaired $t$ test).

To test the possibility that APV might not effectively block NMDA receptors in the present preparations, we observed homosynaptic EPSPs. As shown in Figure 5B, homo-LTP was not induced when APV was applied. The mean ratio of EPSP slope 31-35 min after TBS to that before TBS was $128 \pm 6.0 \%(n=11)$ without APV, whereas it was $97.1 \pm 6.2 \%(n=8)$ with APV. The difference between these two values was significant $(p<0.001$, unpaired $t$ test). These results indicated that hetero-LTD is NMDA receptor independent.

\section{Hetero-LTD is postsynaptic $\mathrm{Ca}^{2+}$ independent}

Then, we addressed the question of whether the induction of hetero-LTD is dependent on an increase in $\mathrm{Ca}^{2+}$ concentration in postsynaptic sites. To answer this question, postsynaptic neurons were filled with a $\mathrm{Ca}^{2+}$ chelator, BAPTA, through recording pipettes. The concentration of BAPTA in the pipettes was $10 \mathrm{~mm}$ and recordings were not initiated until at least $5 \mathrm{~min}$ after the rupture of the cell membrane to allow BAPTA to spread into the neurons. As shown in Figure 5C (hatched circles), TBS induced hetero-LTD of EPSPs at the nontetanized side. The magnitude of hetero-LTD was nearly the same as that of control neurons (open circles). The mean slopes of heterosynaptic EPSPs 31-35 min after TBS for the 11 BAPTA-filled neurons and 8 control neurons were $72.7 \pm 3.2$ and $70.2 \pm 2.8 \%$, respectively. Obviously, the difference between these two values was not significant $(p>0.1$, unpaired $t$ test).

To examine the possibility that BAPTA might not effectively chelate postsynaptic $\mathrm{Ca}^{2+}$ in the present preparations, we observed homosynaptic EPSPs. As shown in Figure 5D, homo-LTP was not induced when BAPTA was injected. The mean ratio of EPSP slope 31-35 min after TBS to that before TBS was $129.7 \pm$ $3.3 \%(n=8)$ without BAPTA, whereas it was $98.0 \pm 5.2 \%(n=$ 11) with BAPTA. The difference between these two values was significant $(p<0.001$, unpaired $t$ test). The results shown in Figure 5, $C$ and $D$, indicated that an increase in $\mathrm{Ca}^{2+}$ concentration in postsynaptic neurons is not necessary to induce heteroLTD at excitatory synapses on these neurons.

\section{Hetero-LTD may be mGluR5 dependent}

The finding that NMDA receptors are not involved in heteroLTD suggests that mGluRs may play a role in this type of LTD. Indeed, a bath application of an antagonist for mGluRs, LY341495, at $100 \mu \mathrm{M}$ (Rao and Daw, 2004) blocked hetero-LTD (Fig. 6A), although this antagonist did not affect the induction of homo-LTP (Fig. 6B). The mean ratios of EPSP slope 31-35 min after TBS to those before TBS at the heterosynaptic pathway were $99.1 \pm 6.3 \%$ with LY341495 $(n=8)$ and $70.7 \pm 4.3 \%$ with vehicle alone $(n=12)$. The difference between these two values was statistically significant ( $p<0.001$, unpaired $t$ test). This antagonist at $100 \mu \mathrm{M}$ is expected to block all types of mGluRs. Then, we applied a selective antagonist for the type 5 of mGluRs, MPEP, at $10 \mu \mathrm{M}$ (Blaabjerg et al., 2001). We found that this selective antagonist also blocked hetero-LTD, although it did not affect homoLTP (Fig. 6C,D). The mean ratios of EPSP slope 31-35 min after TBS to those before TBS at the heterosynaptic pathway were $101.2 \pm 5.1 \%$ with MPEP $(n=8)$ and $72.3 \pm 3.8 \%$ with vehicle alone $(n=9)$. The difference between these two values was statistically significant $(p<0.001$, unpaired $t$ test). These results indicate that hetero-LTD may be mGluR5 dependent.

\section{Endocannabinoids are involved in hetero-LTD}

To elucidate the role of endocannabinoid type 1 receptors $\left(\mathrm{CB}_{1} \mathrm{Rs}\right)$ in hetero-LTD, we examined effects of the $\mathrm{CB}_{1} \mathrm{R}$ antagonist, AM251, on hetero-LTD of EPSPs. The application of AM251 $(5 \mu \mathrm{M})$ through the perfusion medium did not significantly change the baseline level of EPSPs. The mean slope of EPSPs 10-20 min after the application was $104.6 \pm 5.1 \%(n=7)$ of the preapplication value. During the application of AM251, however, TBS became ineffective for the induction of heteroLTD (Fig. 7A). The mean EPSP slope in the heterosynaptic pathway for 10 control cells $31-35$ min after TBS was $74.1 \pm 6.4 \%$ of the baseline, whereas that for 9 AM251-treated cells was $94.1 \pm$ $6.5 \%$. The difference between these two values was significant (unpaired $t$ test, $p<0.001$ ). In the other pathway, AM251 did not block the induction of homo-LTP. The mean EPSP slope for the 10 control cells $31-35$ min after tetanus was $129.0 \pm 6.4 \%$ of the 
A Hetero-pathway (+LY341495)

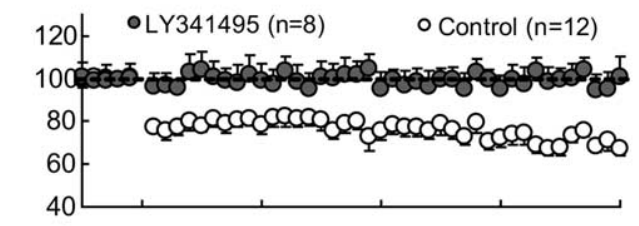

B Homo-pathway (+LY341495)

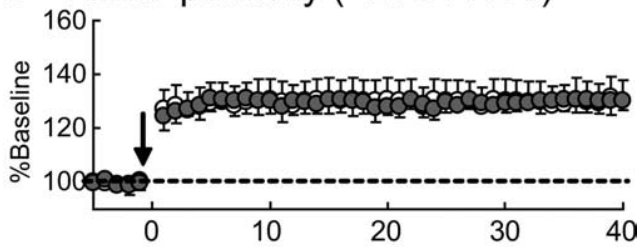

C Hetero-pathway (+MPEP)
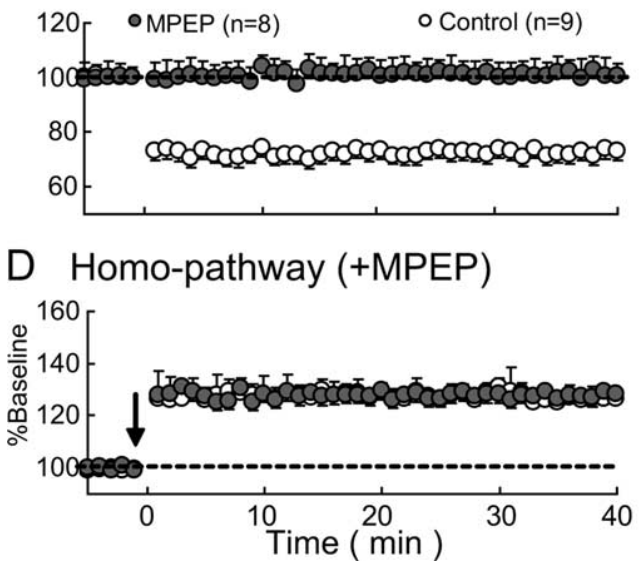

Figure 6. Hetero-LTD is dependent on mGluR5. $\boldsymbol{A}, \boldsymbol{B}$, Mean EPSP slopes plotted against time for heterosynaptic and homosynaptic pathways, respectively, for 8 cells to which LY341495, an antagonist for mGluRs, was applied (hatched circles) and 12 control cells (open circles). Other conventions are the same as those in Figure 2C. C, D, Mean EPSP slopes plotted against time for heterosynaptic and homosynaptic pathways, respectively, for 8 cells to which MPEP, an antagonist for mGluR5, was applied (hatched circles) and 9 control cells (open circles). Other conventions are the same as those in $\boldsymbol{A}$.

baseline, whereas that for the 9 AM251-treated cells was $130.2 \pm$ $8.3 \%$ (Fig. $7 B$ ). Obviously, these two values were not significantly different $(p>0.1$, unpaired $t$ test). These results suggest that endocannabinoids are involved in the induction of hetero-LTD in the developing visual cortex.

Next, we examined whether WIN, an agonist for cannabinoid receptors, depresses excitatory synaptic transmission and occludes hetero-LTD. The application of WIN $(2 \mu \mathrm{M})$ through the medium for 10 min induced slowly growing depression of EPSPs in the heterosynaptic and homosynaptic pathways (Fig. 7C,D, hatched circles). Then, we confirmed that the depressive action of WIN was blocked by the previous application of AM251 at $5 \mu \mathrm{M}$ (Fig. 7C, filled circles). The mean EPSP slopes for the heterosynaptic pathway 13-17 min after initiating the WIN application without and with AM251 were $68.4 \pm 3.9 \%(n=7)$ and $98.6 \pm$ $1.6 \%(n=7)$ of the baseline, respectively. The difference between these two values was significant $(p<0.01$, unpaired $t$ test).

After EPSPs depressed by WIN became stable, tetanic stimulation was applied to one pathway (Fig. $7 D$, downward arrow). Homo-LTP was induced in the tetanized pathway (Fig. 7D). However, significant LTD was not induced in the nontetanized pathway (Fig. 7C, hatched circles). The mean EPSP slope for the
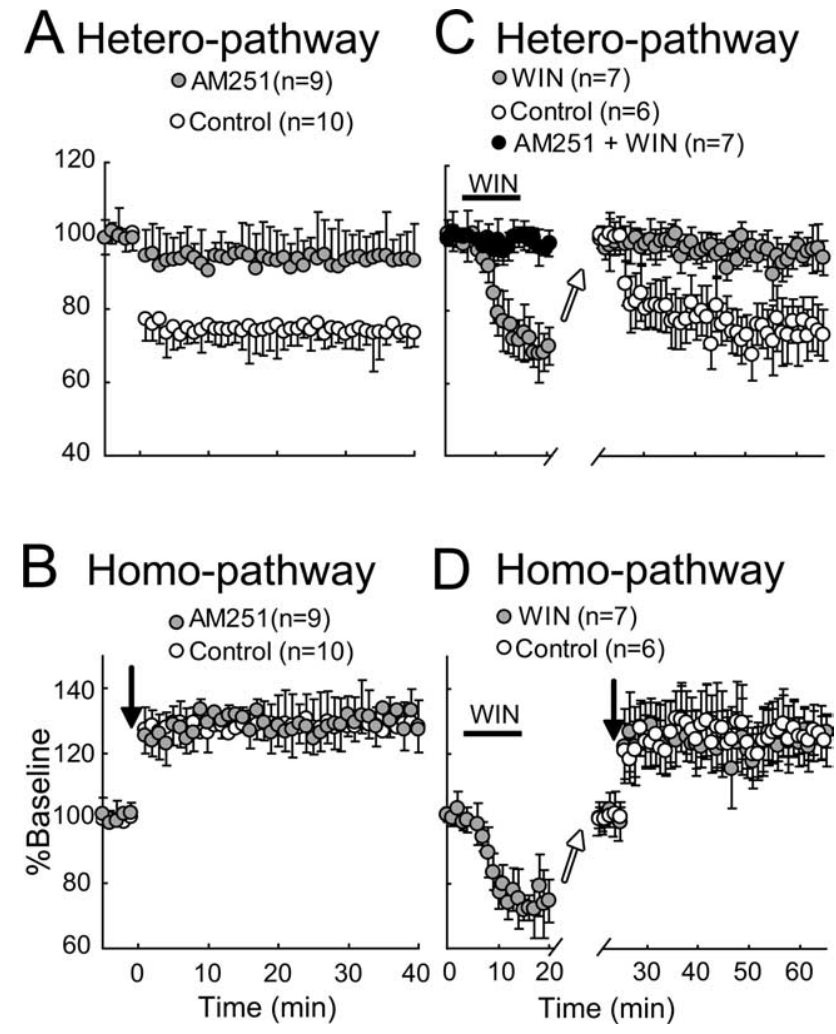

Figure 7. Involvement of $C B_{1} R$ in hetero- $L T D$ and $C B_{1} R$ agonist-induced depression occludes hetero-LTD. $\boldsymbol{A}, \boldsymbol{B}$, Mean EPSP slopes are plotted against time for the heterosynaptic and homosynaptic pathways, respectively, for 9 AM251-treated cells (hatched circles) and 10 control cells (open circles). Other conventions are the same as those in Figure $2 C$. C, D, Time courses of mean EPSP slopes of seven neurons to which WIN, an agonist for $C_{1} R$, was applied, as indicated by a horizontal bar (hatched circles). The filled circles represent mean values for another seven neurons to which AM251 was continuously applied and WIN was transiently applied, as indicated by the horizontal bar. The open arrows indicate that stimulus intensity was increased so as to make the slope equivalent to the value before the administration of WIN. The open circles represent control data for six cells, to which no drug was applied. Other conventions are the same as those in Figure $2 C$.

heterosynaptic pathway $31-35$ min after TBS was $95.3 \pm 4.5 \%$ of the baseline $(n=7)$. The corresponding value for the six control cells was $75.1 \pm 10.5 \%$ of the baseline (Fig. $7 C$, open circles). The difference between these two values was significant $(p<0.01$, unpaired $t$ test). The results shown in Figure 7 suggest that hetero-LTD in the developing visual cortex is mediated by $C B_{1} R$.

\section{Exogenous BDNF blocks hetero-LTD}

Because BDNF is known to prevent the induction of homo-LTD in visual cortical slices (Kinoshita et al., 1999), we examined whether BDNF and its high-affinity receptors are involved also in hetero-LTD. We found that the application of BDNF blocked hetero-LTD, as shown in Figure $8 A$ (hatched circles). The mean ratios of the slope of heterosynaptic EPSP 31-35 min after TBS to that of the baseline were $99.7 \pm 5.6 \%$ with BDNF and $68.6 \pm$ $12.8 \%$ in the control. The difference between these two values was significant ( $p<0.01$, unpaired $t$ test). In the tetanized pathway, exogenously applied BDNF enhanced the magnitude of homo-LTP (Fig. $8 \mathrm{~B}$, hatched circles), as reported previously (Akaneya et al., 1997). The ratios of EPSP of the homosynaptic pathway were $149.8 \pm 4.1 \%$ with BDNF and $126.7 \pm 11.9 \%$ without BDNF. The difference between these two values was significant ( $p<0.01$, unpaired $t$ test).

Then, we addressed the question of whether endogenous 

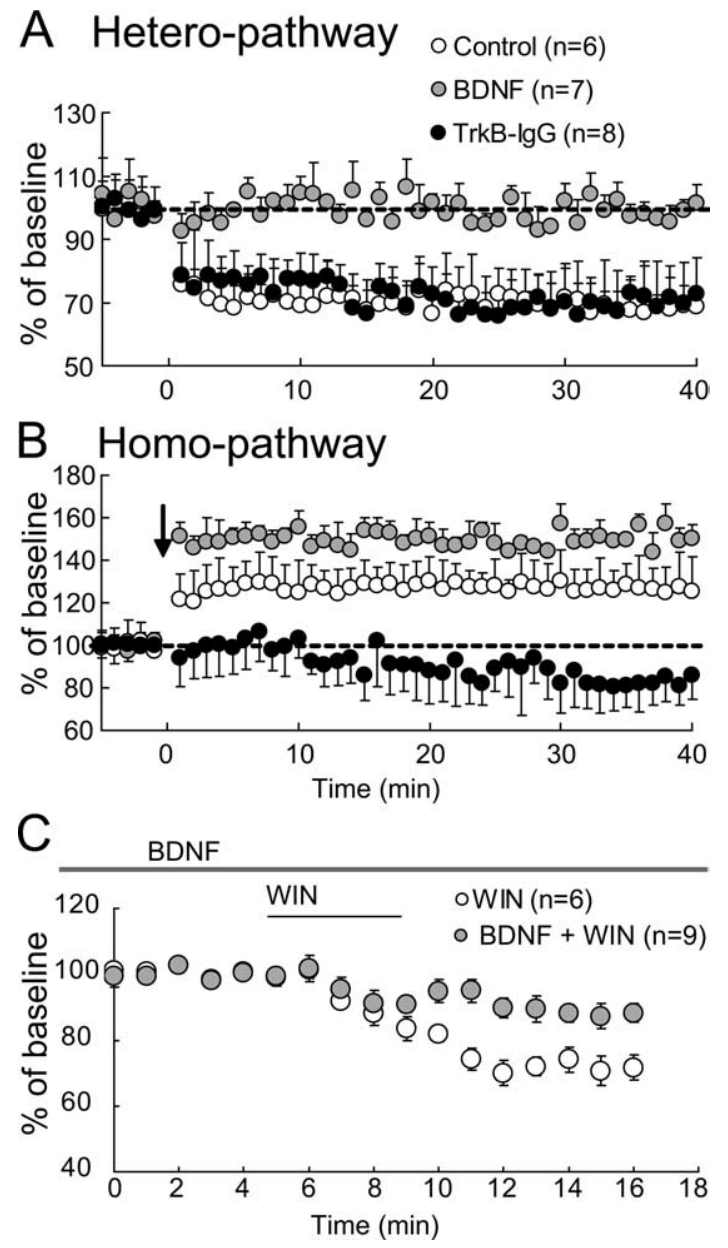

Figure 8. Blockade of hetero-LTD by exogenous BDNF and involvement of endogenous BDNF in homo-LTP. $A, B$, Mean EPSP slopes in the heterosynaptic and homosynaptic pathways, respectively, are plotted against time for seven neurons to which exogenous BDNF was applied (hatched circles) and eight neurons to which TrkB-lgG was applied (filled circles). The open circles indicate data for six control cells without any agent application. Other conventions are the same as those in Figure 2C. C, Mean EPSP slopes in the homosynaptic pathway for six neurons to which WIN was applied (open circles), as indicated by a short horizontal bar, and for nine cells to which exogenous BDNF was continuously applied (hatched circles), as indicated by a long horizontal bar, and WIN was additionally applied, as indicated by the short horizontal bar. Other conventions are the same as those in Figure $2 C$.

BDNF is involved in homo-LTP by applying TrkB-IgG fusion protein, which blocks the function of high-affinity receptors for BDNF, TrkB. We found that the treatment with TrkB-IgG did not significantly change hetero-LTD (Fig. $8 \mathrm{~A}$, filled circles), but rather induced homo-LTD in the tetanized pathway (Fig. $8 B$, filled circles). The mean slope of EPSP in the tetanized pathway $31-35$ min after tetanus was $82.7 \pm 12.7 \%$ of the baseline. This value was significantly ( $p<0.01$, paired $t$ test) smaller than the baseline value. To test the possibility that the appearance of homo-LTD in the tetanized pathway is ascribable to activity of $\mathrm{CB}_{1} \mathrm{R}, \mathrm{AM} 251$ was applied during the treatment with TrkB-IgG (supplemental Fig. 2, available at www.jneurosci.org as supplemental material). The application of AM251 resulted in the emergence of homo-LTP, confirming the above-mentioned possibility.

These results suggest that the BDNF-TrkB system may antagonize the suppressive action of eCBs at presynaptic sites. To examine this possibility, we tested whether BDNF actually blocks the suppressive action of the $\mathrm{CB}_{1} \mathrm{R}$ agonist. As shown in Figure

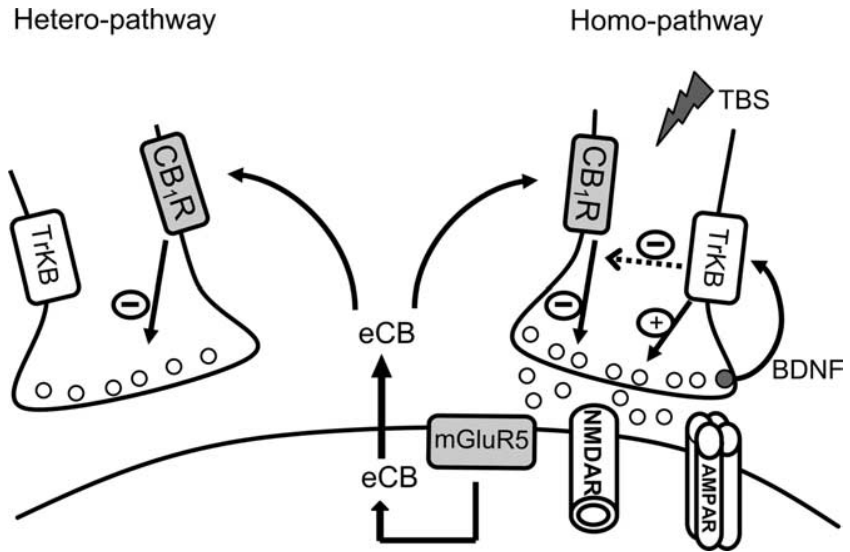

Figure 9. Simplified scheme showing actions of eCBs on homosynaptic and heterosynaptic pathways.

$8 C$, the $\mathrm{CB}_{1} \mathrm{R}$ agonist, WIN, did not strongly suppress EPSPs when slices were treated with exogenous BDNF. The mean slope of EPSPs 6-11 min after cessation of WIN application was $88.5 \pm$ $3.2 \%$ of that before the application (Fig. $8 C$, hatched circles). The somewhat incomplete blockade might be ascribable to the relatively low concentration of exogenously applied BDNF, although we cannot exclude other possibilities. Without BDNF, the application of WIN induced a marked suppression, as mentioned above. The mean slope of EPSPs 6-11 min after cessation of WIN application was $72.7 \pm 3.7 \%$ of that before the application (Fig. $8 C$, open circles). The difference from the value with BDNF was statistically significant ( $p<0.01$, unpaired $t$ test).

\section{Discussion}

The mechanisms underlying the homosynaptic forms of longterm synaptic plasticity (homo-LTP and homo-LTD) in the visual cortex have been intensively studied (for review, see Tsumoto, 1992; Linden and Connor, 1995; Bear, 2003), but those underlying hetero-LTD in the visual cortex have not been well understood. In the present study, we found the following: (1) hetero-LTD of excitatory synapses at layer II/III neurons of the mouse visual cortex is dominant at P7-P10, becomes less dominant with development, and is not induced at P35-P41; (2) the expression locus of this form of LTD is probably presynaptic; (3) this form of LTD is not dependent on the activation of NMDA receptors nor the increase in postsynaptic $\mathrm{Ca}^{2+}$, but dependent on the activation of mGluR5; (4) the type 1 of eCB receptor, $\mathrm{CB}_{1} \mathrm{R}$, is involved in its induction; and (5) activated presynaptic terminals may be protected from eCB-mediated depression by the presynaptic BDNF-TrkB system and consequently activated synapses remain potentiated. These findings are schematically shown in Figure 9.

\section{Contribution of eCBs to hetero-LTD in developing visual cortex}

It was reported that $\mathrm{CB}_{1} \mathrm{Rs}$ are abundantly expressed in the neocortex as well as in the cerebellum and hippocampus (Herkenham et al., 1990; Matsuda et al., 1993; Tsou et al., 1998; Marsicano and Lutz, 1999) (for review, see Freund et al., 2003). A recent study also demonstrated that functional $\mathrm{CB}_{1}$ Rs are expressed in GABAergic and glutamatergic neurons in the hippocampus and neocortex (Katona et al., 2006; Kawamura et al., 2006; Monory et al., 2006; Takahashi and Castillo, 2006; Hill et al., 2007). It is further suggested that $\mathrm{CB}_{1}$ Rs are located on presynaptic termi- 
nals of pyramidal neurons in the neocortex (Domenici et al., 2006). This type of CB receptors is suggested to play a role not only in short-term but also long-term synaptic plasticity (for review, see Chevaleyre et al., 2006).

The involvement of eCBs in the induction of hetero-LTD of GABAergic synapses was reported in the amygdala (Marsicano et al., 2002) and hippocampus (Chevaleyre and Castillo, 2003). A mechanism suggested in these previous studies is a decrease in GABA release from presynaptic terminals. Very recently, eCBmediated hetero-LTD of excitatory synapses has been reported in the immature hippocampus (Yasuda et al., 2008). In the visual cortex, however, there has been no report about the role of eCBs in hetero-LTD, although the involvement of eCBs was reported in the timing-dependent type of homo-LTD in layer $\mathrm{V}$ of the visual cortex (Sjöström et al., 2003) and layer II/III of the somatosensory cortex of young rats (Bender et al., 2006; Nevian and Sakmann, 2006) and in the low-frequency stimulation-induced type of homo-LTD in layer II/III of the visual cortex of young mice (Crozier et al., 2007). These previous studies in the neocortex suggested an involvement of presynaptic NMDA receptors (Sjöström et al., 2003) or postsynaptic $\mathrm{Ca}^{2+}$ signaling (Bender et al., 2006; Nevian and Sakmann, 2006). It is to be noted that all of these previous studies dealt with homo-LTD. The present results suggest that hetero-LTD of excitatory synapses in the developing visual cortex is induced through different mechanisms including presynaptic $\mathrm{CB}_{1}$ Rs.

\section{BDNF protects activated pathways from eCB-mediated depression}

It is known that eCBs rapidly spread through cell membrane by diffusion or a transporting system (Chevaleyre et al., 2006). Then, a question arises why eCBs do not exert their suppressive action on the activated pathway if they spread to adjacent presynaptic sites. In the present study, we found that the blockade of the activity of high-affinity BDNF receptors by TrKB-IgG resulted in the appearance of homo-LTD instead of homo-LTP after TBS of the homosynaptic pathway. Also, we found that exogenously applied BDNF blocked the suppressive action of the $\mathrm{CB}_{1} \mathrm{R}$ agonist on excitatory synaptic responses. These results together suggest that eCBs released from active postsynaptic sites could have suppressed active presynaptic terminals of the homosynaptic pathway, but this action of eCBs was masked by the action of BDNF, because BDNF is released by TBS from presynaptic terminals (Kohara et al., 2001; Lessmann et al., 2003) and enhances the release of conventional transmitters (Carmignoto et al., 1997; Gottschalk et al., 1998; Lessmann and Heumann, 1998). It was reported that an application of BDNF to CNS neurons increases cAMP level, which in turn activates protein kinase A (Cai et al., 1999), although other signaling pathways are also activated (Kaplan and Miller, 2000). The suppressive action of the eCB$\mathrm{CB}_{1} \mathrm{R}$ may be ascribable to the decrease in cAMP in presynaptic terminals (Chevaleyre et al., 2007). Thus, it seems possible that an interaction between the $\mathrm{CB}_{1} \mathrm{R}$ and TrkB pathways at active presynaptic terminals leads to the blockade of action of $\mathrm{CB}_{1} \mathrm{R}$ (Fig. 9).

Then, a question arises why BDNF released from active terminals does not act on heterosynaptic terminals. In slices of the ferret visual cortex, it was reported that the action of BDNF on dendritic growth of cortical neurons is limited within the distance of $4.5 \mu \mathrm{m}$ from the release point (Horch and Katz, 2002). Thus, BDNF released from active terminals may not reach presynaptic sites of the heterosynaptic pathway. Reasons for the limited diffusion of BDNF may be ascribable to its high interactive property with extracellular matrix, proteolysis by the tissue-type plasminogen activator (tPA), or to binding with abundantly expressed TrkB in other components such as postsynaptic sites or glia (Frisén et al., 1993; Pitts and Miller, 2000), although we could not distinguish these possibilities in the present study.

\section{Developmental changes in hetero-LTD}

In the present study, we found that the largest magnitude of hetero-LTD was induced at P7-P10, and this form of LTD was still observed at P14-P20. However, a significant hetero-LTD was not observed at P35-P41. There are at least three possibilities that may account for such a developmental change in hetero-LTD.

First, the expression of $\mathrm{CB}_{1} \mathrm{R}$ in the visual cortex might change with development. For example, it was reported that the level of mRNA expression of $\mathrm{CB}_{1} \mathrm{R}$ in the rat cerebral cortex measured by in situ hybridization was high at $\mathrm{P} 1$ and $\mathrm{P} 5$ and became very low in the adult, although the specific $\mathrm{CB}_{1} \mathrm{R}$ binding assessed by radioautography in the adult was higher than that at P1 and P5 (Berrendero et al., 1999). By immunohistochemistry, however, it was reported that $\mathrm{CB}_{1} \mathrm{R}$ immunoreactivity appeared in layer II/III of the rat somatosensory cortex around P6, becoming very intense by P12-P16, and then remained high in the adult (Deshmukh et al., 2007). Thus, the developmental changes in the expression level of $\mathrm{CB}_{1}$ Rs assessed by different methods in the cerebral cortex seemed not completely consistent with each other, and the disappearance of hetero-LTD in the adult might not be explained solely by the developmental changes in $\mathrm{CB}_{1} \mathrm{Rs}$ in the visual cortex.

The second possibility that may account for the developmental changes in hetero-LTD is the change in the probability of transmitter release from presynaptic terminals. It is well known that the release probability of transmitters decreases with postnatal development in the hippocampus, somatosensory cortex, and other brain areas (Bolshakov and Siegelbaum, 1995; Pouzat and Hestrin, 1997; Iwasaki and Takahashi, 2001; Yanagisawa et al., 2004). Thus, the suppressive action of eCBs is expected to be less effective if the release probability becomes lower with development.

The third possibility is related to the developmental upregulation of BDNF expression and diffusion in cortical tissues. It was reported that the expression of BDNF developed relatively late (Huang et al., 1999), and the activity of tPA in the mouse visual cortex is very high at P15-P17 and then reduced with development (Mataga et al., 2004). In the matured cortex, therefore, the increased release of BDNF from active terminals and less restricted diffusion of BDNF that eludes proteolysis may act also on the nonactivated terminals.

\section{Physiological roles of eCB-mediated hetero-LTD in developing visual cortex}

The activity-dependent strengthening and weakening of synapses are considered to be the basis of the refinement of neural circuits during postnatal development (Singer, 1995; Zhang and Poo, 2001). In the developing visual cortex, hetero-LTD is hypothesized to play a role in modification of neural circuits after monocular visual deprivation (for review, see Tsumoto, 1992; Bear, 2003) (but see Hensch, 2005), although a few studies rather suggested that homo-LTD plays such a role (Rittenhouse et al., 1999; Heynen et al., 2003). Thus, eCB-mediated LTD at the heterosynaptic pathway might be involved in such an experiencedependent alteration of neuronal circuits in the developing visual cortex. 
Another functional role of the $\mathrm{eCB}-\mathrm{CB}_{1} \mathrm{R}$ system may be a substitute of the GABAergic inhibitory system in the immature visual cortex. In the prenatal and early stages of postnatal development of the cortex, GABAergic synapses, the major inhibitory system in the mature brain, are poorly developed or even excitatory (Yuste and Katz, 1991; Lin et al., 1994) (for review, see BenAri, 2002). Thus, the GABAergic inhibitory system may not effectively operate in the neonatal cortex. The present results indicate that, in place of GABA, eCBs serve to reduce glutamatergic excitatory transmission in the developing visual cortex, because they also depress GABAergic excitatory transmission (Bernard et al., 2005).

\section{References}

Abraham WC, Goddard GV (1983) Asymmetric relations between homosynaptic long-term potentiation and heterosynaptic long-term depression. Nature 305:717-719.

Akaneya Y, Tsumoto T, Kinoshita S, Hatanaka H (1997) Brain-derived neurotrophic factor enhances long-term potentiation in rat visual cortex. J Neurosci 17:6707-6716.

Artola A, Singer W (1987) Long-term potentiation and NMDA receptors in rat visual cortex. Nature 330:649-652.

Bear MF (2003) Bidirectional synaptic plasticity: from theory to reality. Philos Trans R Soc Lond B Biol Sci 358:649-655.

Bear MF, Abraham WC (1996) Long-term depression in hippocampus. Annu Rev Neurosci 19:437-462.

Ben-Ari Y (2002) Excitatory actions of GABA during development: the nature of the nurture. Nat Rev Neurosci 3:728-739.

Bender VA, Bender KJ, Brasier DJ, Feldman DE (2006) Two coincidence detectors for spike timing-dependent plasticity in somatosensory cortex. J Neurosci 26:4166-4177.

Bernard C, Milh M, Morozov YM, Ben-Ari Y, Freund TF, Gozlan H (2005) Altering cannabinoid signaling during development disrupts neuronal activity. Proc Natl Acad Sci U S A 102:9388-9393.

Berrendero F, Sepe N, Ramos JA, Di Marzo V, Fernández-Ruiz JJ (1999) Analysis of cannabinoid receptor binding and mRNA expression and endogenous cannabinoid contents in the developing rat brain during late gestation and early postnatal period. Synpase 33:181-191.

Blaabjerg M, Kristensen BW, Bonde C, Zimmer J (2001) The metabotropic glutamate receptor agonist $1 S, 3 R$-ACPD stimulates and modulates NMDA receptor mediated excitotoxicity in organotypic hippocampal slice cultures. Brain Res 898:91-104.

Bolshakov VY, Siegelbaum SA (1995) Regulation of hippocampal transmitter release during development and long-term potentiation. Science 269:1730-1734.

Cai D, Shen Y, De Bellard M, Tang S, Filbin MT (1999) Prior exposure to neurotrophins blocks inhibition of axonal regeneration by MAG and myelin via cAMP-dependent mechanism. Neuron 22:89-101.

Carmignoto G, Pizzorusso T, Tia S, Vicini S (1997) Brain-derived neurotrophic factor and nerve growth factor potentiate excitatory synaptic transmission in the rat visual cortex. J Physiol 498:153-164.

Chevaleyre V, Castillo PE (2003) Heterosynaptic LTD of hippocampal GABAergic synapses: a novel role of endocannabinoids in regulating excitability. Neuron 38:461-472.

Chevaleyre V, Takahashi KA, Castillo PE (2006) Endocannabinoidmediated synaptic plasticity in the CNS. Annu Rev Neurosci 29:37-76.

Chevaleyre V, Heifets BD, Kaeser PS, Südhof TC, Purpura DP, Castillo PE (2007) Endocannabinoid-mediated long-term plasticity requires cAMP/ PKA signaling and RIM1 $\alpha$. Neuron 54:801-812.

Crozier RA, Wang Y, Liu CH, Bear MF (2007) Deprivation-induced synaptic depression by distinct mechanisms in different layers of mouse visual cortex. Proc Natl Acad Sci U S A 104:1383-1388.

Deshmukh S, Onozuka K, Bender KJ, Bender VA, Lutz B, Mackie K, Feldman DE (2007) Postnatal development of cannabinoid receptor type 1 expression in rodent somatosensory cortex. Neuroscience 145:279-287.

Domenici MR, Azad SC, Marsicano G, Schierloh A, Wotjak CT, Dodt HU, Zieglgänsberger W, Lutz B, Rammes G (2006) Cannabinoid receptor type 1 located on presynaptic terminals of principal neurons in the forebrain controls glutamatergic synaptic transmission. J Neurosci 26:5794-5799.

Doyère V, Srebro B, Laroche S (1997) Heterosynaptic LTD and depotentia- tion in the medial perforant path of the dentate gyrus in the freely moving rat. J Neurophysiol 77:571-578.

Faber DS, Korn H (1991) Applicability of the coefficient of variation method for analyzing synaptic plasticity. Biophys J 60:1288-1294.

Freund TF, Katona I, Piomelli D (2003) Roles of endogenous cannabinoids in synaptic signaling. Physiol Rev 83:1017-1066.

Frisén J, Verge VM, Fried K, Risling M, Persson H, Trotter J, Hökfelt T, Lindholm D (1993) Characterization of glial trkB receptors: differential response to injury in the central and peripheral nervous systems. Proc Natl Acad Sci U S A 90:4971-4975.

Gerdeman GL, Ronesi J, Lovinger DM (2002) Postsynaptic endocannabinoid release is critical to long-term depression in the striatum. Nat Neurosci 5:446-451.

Gottschalk W, Pozzo-Miller LD, Figurov A, Lu B (1998) Presynaptic modulation of synaptic transmission and plasticity by brain-derived neurotrophic factor in the developing hippocampus. J Neurosci 18:6830-6839.

Hensch TK (2005) Critical period plasticity in local cortical circuits. Nat Rev Neurosci 6:877-888.

Herkenham M, Lynn AB, Little MD, Johnson MR, Melvin LS, de Costa BR, Rice KC (1990) Cannabinoid receptor localization in brain. Proc Natl Acad Sci U S A 87:1932-1936.

Heynen AJ, Yoon BJ, Liu CH, Chung HJ, Huganir RL, Bear MF (2003) Molecular mechanism for loss of visual cortical responsiveness following brief monocular deprivation. Nat Neurosci 6:854-862.

Hill EL, Gallopin T, Férézou I, Cauli B, Rossier J, Schweitzer P, Lambolez B (2007) Functional CB1 receptors are broadly expressed in neocortical GABAergic and glutamatergic neurons. J Neurophysiol 97:2580-2589.

Horch HW, Katz LC (2002) BDNF release from single cells elicits local dendritic growth in nearby neurons. Nat Neurosci 5:1177-1184.

Huang ZJ, Kirkwood A, Pizzorusso T, Porciatti V, Morales B, Bear MF, Maffei L, Tonegawa S (1999) BDNF regulates the maturation of inhibition and the critical period of plasticity in mouse visual cortex. Cell 98:739-755.

Iwasaki S, Takahashi T (2001) Developmental regulation of transmitter release at the calyx of Held in rat auditory brainstem. J Physiol 534:861-871.

Kaplan DR, Miller FD (2000) Neurotrophin signal transduction in the nervous system. Curr Opin Neurobiol 10:381-391.

Katona I, Urbán GM, Wallace M, Ledent C, Jung KM, Piomelli D, Mackie K, Freund TF (2006) Molecular composition of the endocannabinoid system at glutamatergic synapses. J Neurosci 26:5628-5637.

Kawamura Y, Fukaya M, Maejima T, Yoshida T, Miura E, Watanabe M, Ohno-Shosaku T, Kano M (2006) The CB1 cannabinoid receptor is the major cannabinoid receptor at excitatory presynaptic sites in the hippocampus and cerebellum. J Neurosci 26:2991-3001.

Kimura F, Nishigori A, Shirokawa T, Tsumoto T (1989) Long-term potentiation and $\mathrm{N}$-methyl-D-aspartate receptors in the visual cortex of young rats. J Physiol 414:125-144.

Kinoshita S, Yasuda H, Taniguchi N, Katoh-Semba R, Hatanaka H, Tsumoto $\mathrm{T}$ (1999) Brain-derived neurotrophic factor prevents low-frequency inputs from inducing long-term depression in the developing visual cortex. J Neurosci 19:2122-2130.

Kohara K, Kitamura A, Morishima M, Tsumoto T (2001) Activitydependent transfer of brain-derived neurotrophic factor to postsynaptic neurons. Science 291:2419-2423.

Lessmann V, Heumann R (1998) Modulation of unitary glutamatergic synapses by neurotrophin $4 / 5$ or brain-derived neurotrophic factor in hippocampal microcultures: presynaptic enhancement depends on preestablished paired-pulse facilitation. Neuroscience 86:399-413.

Lessmann V, Gottmann K, Malcangio M (2003) Neurotrophin secretion: current facts and future prospects. Prog Neurobiol 69:341-374.

Levy WB, Steward O (1979) Synapses as associative memory elements in the hippocampal formation. Brain Res 175:233-245.

Lin MH, Takahashi MP, Takahashi Y, Tsumoto T (1994) Intracellular calcium increase induced by GABA in visual cortex of fetal and neonatal rats and its disappearance with development. Neurosci Res 20:85-94.

Linden DJ, Connor JA (1995) Long-term synaptic depression. Annu Rev Neurosci 18:319-357.

Malenka RC, Bear MF (2004) LTP and LTD: an embarrassment of riches. Neuron 44:5-21.

Marsicano G, Lutz B (1999) Expression of the cannabinoid receptor CB1 in distinct neuronal subpopulations in the adult mouse forebrain. Eur J Neurosci 11:4213-4225.

Marsicano G, Wotjak CT, Azad SC, Bisogno T, Rammes G, Cascio MG, 
Hermann H, Tang J, Hofmann C, Zieglgänsberger W, Di Marzo V, Lutz B (2002) The endogenous cannabinoid system controls extinction of aversive memories. Nature 418:530-534.

Mataga N, Mizuguchi Y, Hensch TK (2004) Experience-dependent pruning of dendritic spines in visual cortex by tissue plasminogen activator. Neuron 44:1031-1041.

Matsuda LA, Bonner TI, Lolait SJ (1993) Localization of cannabinoid receptor mRNA in rat brain. J Comp Neurol 327:535-550.

Monory K, Massa F, Egertová M, Eder M, Blaudzun H, Westenbroek R, Kelsch W, Jacob W, Marsch R, Ekker M, Long J, Rubenstein JL, Goebbels S, Nave KA, During M, Klugmann M, Wölfel B, Dodt HU, Zieglgänsberger W, Wotjak CT, et al. (2006) The endocannabinoid system controls key epileptogenic circuit in the hippocampus. Neuron 51:455-466.

Nevian T, Sakmann B (2006) Spine $\mathrm{Ca}^{2+}$ signaling in spike-timing dependent plasticity. J Neurosci 26:11001-11013.

Pitts AF, Miller MW (2000) Expression of nerve growth factor, brainderived neurotrophic factor, and neurotrophin-3 in the somatosensory cortex of the mature rat: coexpression with high-affinity neurotrophin receptors. J Comp Neurol 418:241-254.

Pouzat C, Hestrin S (1997) Developmental regulation of basket/stellate cell $\rightarrow$ Purkinje cell synapses in the cerebellum. J Neurosci 17:9104-9112.

Rao Y, Daw NW (2004) Layer variations of long-term depression in rat visual cortex. J Neurophysiol 92:2652-2658.

Rittenhouse CD, Shouval HZ, Paradiso MA, Bear MF (1999) Monocular deprivation induces homosynaptic long-term depression in visual cortex. Nature 397:347-350.

Singer W (1995) Development and plasticity of cortical processing architectures. Science 270:758-764.

Sjöström PJ, Turrigiano GG, Nelson SB (2003) Neocortical LTD via coinci- dent activation of presynaptic NMDA and cannabinoid receptors. Neuron 39:641-654.

Takahashi KA, Castillo PE (2006) The CB1 cannabinoid receptor mediates glutamatergic synaptic suppression in the hippocampus. Neuroscience 139:795-802.

Tamura H, Tsumoto T, Hata Y (1992) Activity-dependent potentiation and depression of visual cortical responses to optic nerve stimulation in kittens. J Neurophysiol 68:1603-1612.

Tsou K, Brown S, Sañudo-Peña MC, Mackie K, Walker JM (1998) Immunohistochemical distribution of cannabinoid $\mathrm{CB} 1$ receptors in the rat central nervous system. Neuroscience 83:393-411.

Tsumoto T (1992) Long-term potentiation and long-term depression in the neocortex. Prog Neurobiol 39:209-228.

Tsumoto T, Suda K (1979) Cross-depression: an electrophysiological manifestation of binocular competition in the developing visual cortex. Brain Res 168:190-194.

Yanagisawa T, Tsumoto T, Kimura F (2004) Transiently higher release probability during critical period at thalamocortical synapses in the mouse barrel cortex: relevance to differential short-term plasticity of AMPA and NMDA EPSCs and possible involvement of silent synapses. Eur J Neurosci 20:3006-3018.

Yasuda H, Huang Y, Tsumoto T (2008) Regulation of excitability and plasticity by endocannabinoids and PKA in developing hippocampus. Proc Natl Acad Sci U S A 105:3106-3111.

Yuste R, Katz LC (1991) Control of postsynaptic $\mathrm{Ca}^{2+}$ influx in developing neocortex by excitatory and inhibitory neurotransmitters. Neuron 6:333-344.

Zhang LI, Poo MM (2001) Electrical activity and development of neural circuits. Nat Neurosci 4 [Suppl]:1207-1214.

Zucker RS (1989) Short-term synaptic plasticity. Annu Rev Neurosci 12:13 31 . 